\title{
EXPERIMENTAL STUDY OF THE VOLATILE PETROLEUM PRODUCTS EFFECT ON THE CENTRAL NERVOUS SYSTEM
}

\author{
RAGIM ALMAMED ORUJOV ${ }^{1 *}$, RANA ANVER JAFAROVA ${ }^{2}$
}

${ }^{1}$ Department of Hygiene of Children, Teenagers and Occupational Hygiene, Azerbaijan Medical University, Bakichanov Str., 23, Baku, AZ 1022, Azerbaijan. ${ }^{2}$ Research Center of the Azerbaijan Medical University, Bakichanov Str., 23, Baku, AZ 1022, Azerbaijan.

Email: Orujov-2017@yandex.ru

Received: 27 July 2017, Revised and Accepted: 11 December 2017

ABSTRACT

Objective: The goal of the research is studying the functional changes in the central nervous system against the background of intoxication with the minimum dosages of gasoline, benzene and acetone.

Methods: The research was performed on 45 white mice divided into 3 groups; each group received corresponding hydrocarbon in the exposure chamber by inhaling. The functional state of the CNS was assessed with a complex of integral tests: By summation of subliminal pulses, the ability of animals to restore rectilinear movement after centrifugation, by the tone of skeletal muscles, and by the activity of muscle static work.

Results: The durations of the narcosis phases in case of acute inhalation poisoning are different for all studied substances. The study of the functional changes in the CNS on the background of intoxication with low dosages has revealed that at the first exposure to benzene for activating the motor reaction the required number of electric pulses from the outside increases, the muscle tone increases, the ability to static work reduces, and the time for rectilinear movement and "animal hypnosis" increases. At the same time, on the background of intoxication during the fifth exposure, a decrease is observed in the number of electric pulses from the outside for activating the motor reaction, the muscle tone remains increased, the ability to static work is reduced, and the time of "animal hypnosis" is shorter than that during the first exposure.

Conclusion: Against the background of the repeated use of small doses of benzene, the CNS adapts to the action of the toxic factor. With that, the ability of the CNS to sum the subliminal pulses, the cholinergic innervation of the skeletal muscles tone and other integral tests during the fifth exposure change less than during the first exposure.

Keywords: Central nervous system, Exposure to benzene, Muscle tone, Subliminal pulses, Animal hypnosis, Static work.

(c) 2018 The Authors. Published by Innovare Academic Sciences Pvt Ltd. This is an open access article under the CC BY license (http://creativecommons. org/licenses/by/4. 0/) DOI: http://dx.doi.org/10.22159/ajpcr.2018.v11i3.21587

\section{INTRODUCTION}

The most common technogeneous environmental pollutants today are extraction and processing of oil, using refined petroleum products in the industry and everyday life [1,2]. Pollution of the environment - air, soil, and water resources - is due to exhaust gases, burning fuel in the industrial scale, production, and use of organic solvents. Accumulating in the human environment, oil hydrocarbons have adverse effects on health. In high concentrations, these chemicals cause acute poisoning with specific symptoms $[3,4]$. At the same time, small dosages of these substances, in case of long exposure can deteriorate protective functions of the nonspecific immune system, which opens a way for the development of serious diseases [5,6]. Especially alarming is the fact that children and women of reproductive age are affected first $[7,8]$. That is why in 1982, an expert group of the UN that deals with the impact of environmental and anthropogenic factors on living organisms made a conclusion that environmental pollution results in irreversible negative consequences for health, and that pollution by hydrocarbons, heavy metals, radioactive waste is first and foremost among the factors that are most dangerous to human health [9-12].

Getting into the organism, hydrocarbons are dissolved in blood, absorbed by tissues rich in fat and lipids, and almost without entering into chemical interaction with the biological substrate act as non-specific stimuli, causing a reaction that is characteristic of the tissue in which they are located. Such an object rich in fats and lipids is the central nervous system (CNS), the reaction of which is expressed in excitation, inhibition, and narcosis. It should be noted that hydrocarbons with strong lipophilicity from the blood are rapidly absorbed into the nervous tissue, but are also rapidly eliminated, while hydrocarbons with low lipophilicity are adsorbed slowly, and are retained in the tissues of CNS for longer periods [2,13].

Given all the above, and the important role of the CNS in the regulation of adaptogenic functions of the organism, it becomes evident that it is important to study the toxic effects on the CNS of certain oil distillation products widely used today - acetone, gasoline, and benzene, which are industrial drugs. The studied chemicals are different from each other in their physicochemical properties; therefore, they have a different period of semi-elimination from the organism: Acetone adsorbs slowly and is retained in the CNS longer; gasoline is quickly adsorbed and is quickly withdrawn, benzene is absorbed into the CNS slower than gasoline, but faster than acetone. Despite the fact that this issue has been widely covered in the scientific literature, some aspects require a more detailed study. Therefore, we considered it appropriate to perform an experimental study of the acute toxic effect of the minimum narcotic concentrations of acetone, benzene, and gasoline in case of inhalation. 


\section{METHODS}

The experiment was made with 45 white mice weighing 18-22 g, divided into 3 groups, 15 animals in each. The group 1 was exposed to inhalation of acetone at the dosage of $99.0 \mathrm{mg} / \mathrm{l}$, group 2 - to inhalation of gasoline at the dosage of $65.0 \mathrm{mg} / \mathrm{l}$, and group 3 - to inhalation of benzene at the dosage of $32.6 \mathrm{mg} / \mathrm{l}$.

The inhalation dosages corresponded to the minimum ones for each hydrocarbon in drug concentrations. Given that adaptation to hydrocarbons may be caused not only by chronic action but also by repeated acute intoxications, exposure of animals was made with the minimum drug concentrations for each hydrocarbon, with repeated periods of 2 days with acute experiments. Animals were exposed 5 times in special chambers with the volume of $700 \mathrm{~L}$. With that, the number of animals in the chambers, in respect to their volume, was calculated to create the same conditions of oxygen content in them for the exposure. The air in the chambers was continuously mixed with a fan.

To assess the response reactions of the experimental animals' organisms, tests that would let identifying a set of integral indicators of the functional state of the CNS were used:

1. The functional state of the CNS was assessed by summing subliminal pulses in the following manner: The hind limbs of the mouse were placed on metal electrodes to place one paw on one electrode, and the other limb - on the other one. Subliminal irritation electric shocks were made until the limb was withdrawn from the electrode. The frequency of the pulses was 2 pulses $/ \mathrm{s}$, the duration was $0.2 \mathrm{~m} / \mathrm{s}$, the pauses were $3.5 \mathrm{~s}$, and the voltage was $30 \mathrm{~V}$. Each mouse was tested 3 times, based on which the average value was calculated.

2. The ability of white mice to restore rectilinear movement was studied by the method of "centrifuging" the animals after they have left the drugged state. Rotation in the centrifuge lasted for $20 \mathrm{~s}$ at $600-700 \mathrm{rpm}$. The time from the animal withdrawal from the holder after centrifuging until the recovery of rectilinear movement included two phases: During the first one, the animals remained motionless, during the second one, the animals moved in a circle. Only after that, the animals acquired the ability to rectilinear movement.

3. The state of skeletal muscles innervation with cholinergic structures of the CNS was assessed by the muscle tone. The test was performed as follows: A white mouse was kept in the vertical position; in this position, animals hind limbs spread as their muscle tone weakens, thus, increasing the distance between the outer fingers, while as the muscle tone increases, the distance reduces.

4. The indicators that show the functional state of the CNS include performing static muscular work by the experimental animals. The essence of the test is that a mouse that is suspended on a vertically lowered lace performs static work by holding in order not to fall. The duration of time of holding on the lace defines the ability to perform static work.

When not participating in the experiments, all animals were kept and fed in the same conditions. All experiments on animals were performed according to the "European Convention for Protection of Vertebrate Animals Used for Experimental and Other Scientific Purposes," Strasbourg, March 18, 1986.

Statistically significant differences between the compared groups were established with the use of parametric Student's t-test. Mean values $(\mathrm{M})$, average errors of mean values $(\mathrm{m})$, standard deviation $(\sigma)$, and the " $t$ "-criterion were determined. The causal relationships between exposures and their effect were determined using multivariate correlation analyses.

\section{RESULTS}

The results of the narcotic effect of the studied hydrocarbons are shown in Table 1. Table 1 shows, if excitation and inhibition in experimental animals precede the narcotic effect, their first manifestations are expressed in transient narcosis. The time of its occurrence is longer with acetone than that with gasoline $(41.1 \pm 0.87 \mathrm{~min}$ and $31.9 \pm 0.91 \mathrm{~min}$, respectively, $\mathrm{p}<0.001)$. However, strong narcosis occurs sooner with acetone than with gasoline $(2.94 \pm 0.39 \mathrm{~min}$ and $8.53 \pm 0.85 \mathrm{~min}$, respectively, $\mathrm{p}<0.001$ ), and in the chamber, it lasts almost the same time (15.47 \pm 0.32 min and $19.67 \pm 1.06$ min, respectively, $\mathrm{p}<0.5)$.

As the obtained results show, by the time of occurrence and duration, excitation, and inhibition phases of the studied narcotics are different: Compared to acetone, excitation occurs sooner with gasoline, but inhibition lasts longer. With that, both these phases should be viewed as a single mutually correlating process. Based on the physicochemical differences, it could be expected that the benzene narcosis will come later than the gasoline one, but it turned out that benzene causes transient narcosis much earlier (the time of occurrence of transient narcosis with gasoline is $31.9 \pm 0.91 \mathrm{~min}$, with benzene $-9.73 \pm 2.0 \mathrm{~min}$, $\mathrm{p}<0.002$ ), and it lasts longer. Therefore, the phase of the excitation in case of benzene intoxication is shorter, and inhibition is longer than that in case of intoxication with gasoline.

Apparently, during the time of exposure, equilibrium concentrations are reached in the organism and the alveolar air of the animals. At the end of the exposure, the time of hydrocarbons removal, and consequently, the time of recovery from narcosis should be different in accordance with physicochemical difference between the hydrocarbons. This relation is in place under the action of acetone and gasoline, which results in the significantly longer duration of non-transient acetone narcosis outside the chamber $(p<0.001)$. At the same time, benzene is characterized by the fact that the duration of non-transient narcosis outside the chamber $(7.94 \pm 1.19 \mathrm{~min})$ is much shorter than that in case of narcosis with acetone (123.03 $\pm 9.8 \mathrm{~min}, \mathrm{p}<0.001)$, and with gasoline $(24.7 \pm 2.43 \mathrm{~min}, \mathrm{p}<0.001)$.

After recovering from narcosis, recovery of animals' orientation reaction was assessed by animals getting away from the edge of the table to keep from falling. The orientation reaction recovered in the animals in the following sequence: After poisoning with gasoline for $2.11 \pm 0.46$ minutes, after benzene narcosis for $5.6 \pm 0.9763 \mathrm{~min}, \mathrm{p}<0.001$, and, finally, after acetone narcosis for $7.0 \pm 0.63 \mathrm{~min}, \mathrm{p}<0.001$.

Benzene is the most toxic of the industrial narcotics mentioned above. Therefore, we studied its effect on the CNS in more detail. It turned out that it causes the long-term first phase of narcosis, which occurs at the high level of lability. In case of five times exposure, adaptation may be judged by the reduced duration of the narcosis (Table 2). We can assume that the fifth exposure occurred on an already adapted organism.

With the increased phase of transient narcosis $(\mathrm{p}<0.001)$, non-transient narcosis decreased sharply $(\mathrm{p}<0.001)$; the time of recovery from narcosis reduced. These data show that upon adaptation of animals to the action of benzene, the duration of the excitation phase increases, and thereby the overall duration of non-transient narcosis reduces $(42.91 \pm 4.08$ or $16.90 \pm 4.85 ; \mathrm{p}<0.001)$.

The functional state of the CNS may be judged by the number of integral tests (Table 3). One of such tests is the ability of the CNS to sum the subliminal pulses at the frequency of pulses of $2 \mathrm{~ms}$, with the duration of $0.2 \mathrm{~ms}$, with a pause of $3.5 \mathrm{~s}$. With that, the voltage that triggered the motor response was $30 \mathrm{~V}$. During the successive irritations of the afferent nerve with electric current at the subliminal level, motor reflex occurs. An increased number of pulses indicates decreased excitability. During the first exposure, the number of pulses increased on the average by 4.53 and reached $10.41 \pm 1.79$, and this increase was on the verge of statistical significance level $(\mathrm{p}<0.1)$. During the fifth exposure of animals, an increased number of pulses by 1.73 was registered with low significance level (up to $6.54 \pm 2.09$ instead of $4.81 \pm 1.14$ before exposure, $\mathrm{p}<0.5$ ). These data indicate that after adaptation to the repeated action of benzene, there is no significant change in the excitability of the CNS.

Innervation of skeletal muscles with cholinergic structures, on which the muscle tone depends, is widely known. Our observations 
Table 1: Duration of narcosis phases in case of acute inhalation poisoning of white mice with organic solvents

\begin{tabular}{|c|c|c|c|c|c|c|c|}
\hline \multirow{2}{*}{\multicolumn{2}{|c|}{$\begin{array}{l}\text { Hydrocarbons, concentrations, } \\
\text { number of animals }(n=15)\end{array}$}} & \multicolumn{6}{|c|}{ Phases of narcotic action, minutes } \\
\hline & & \multirow{2}{*}{$\begin{array}{l}\text { Until transient } \\
\text { narcosis }\end{array}$} & \multirow{2}{*}{$\begin{array}{l}\text { Transient } \\
\text { narcosis }\end{array}$} & \multicolumn{3}{|c|}{ Non-transient narcosis } & \multirow{2}{*}{$\begin{array}{l}\text { Recovery of the } \\
\text { orientation reaction }\end{array}$} \\
\hline & & & & $\begin{array}{l}\text { In the } \\
\text { chamber }\end{array}$ & $\begin{array}{l}\text { Outside the } \\
\text { chamber }\end{array}$ & Overall duration & \\
\hline \multirow{6}{*}{$\begin{array}{l}\text { Duration in } \\
\text { minutes }\end{array}$} & Acetone, $99.0 \mathrm{mg} / \mathrm{l}$ & $41.1 \pm 0.87$ & $2.94 \pm 0.39$ & $15.47 \pm 0.32$ & $123.03 \pm 9.8$ & $138.50 \pm 9.38$ & $7.0 \pm 0.63$ \\
\hline & Gasoline, $65.0 \mathrm{mg} / \mathrm{l}$ & $31.9 \pm 0.91$ & $8.53 \pm 0.85$ & $19.67 \pm 1.06$ & $24.7 \pm 2.43$ & $44.37 \pm 3.16$ & $2.11 \pm 0.46$ \\
\hline & $\mathrm{p}<$ & 0.001 & 0.001 & 0.5 & 0.001 & 0.001 & 0.001 \\
\hline & Benzene, $32.6 \mathrm{mg} / \mathrm{l}$ & $9.73 \pm 2.0$ & $23.6 \pm 2.1$ & $26.67 \pm 2.3$ & $7.94 \pm 1.19$ & $34.6 \pm 3.05$ & $5.6 \pm 0.97$ \\
\hline & $\mathrm{p}<$ & 0.001 & 0.001 & 0.001 & 0.001 & 0.001 & 0.2 \\
\hline & $\mathrm{p}_{1}<$ & 0.02 & 0.001 & 0.01 & 0.001 & 0.02 & 0.001 \\
\hline
\end{tabular}

Significance of difference: With acetone $-\mathrm{p}$, with gasoline $-\mathrm{p}_{1}$.

Table 2: The duration of the phases of benzene narcosis in case of single and repeated inhalation exposure of animals

\begin{tabular}{|c|c|c|c|c|}
\hline \multirow[t]{2}{*}{ Times of exposure } & \multicolumn{4}{|l|}{ Narcosis phases, minutes } \\
\hline & Until transient narcosis & $\begin{array}{l}\text { Transient } \\
\text { narcosis }\end{array}$ & $\begin{array}{l}\text { Non-transient narcosis in the } \\
\text { chamber }\end{array}$ & $\begin{array}{l}\text { Recovery from narcosis outside the } \\
\text { chamber }\end{array}$ \\
\hline First & $10.75 \pm 1.50$ & $14.09 \pm 1.33$ & $35.16 \pm 2.57$ & $7.75 \pm 1.51$ \\
\hline Fifth & $11.54 \pm 1.33$ & $36.19 \pm 3.33$ & $12.27 \pm 3.71$ & $4.63 \pm 1.14$ \\
\hline $\mathrm{p}<$ & 0.05 & 0.001 & 0.001 & 0.01 \\
\hline
\end{tabular}

Table 3: Indicators of the functional state of the central nervous system

\begin{tabular}{llll}
\hline Indicators & \multicolumn{2}{l}{ The number of exposure, and the } \\
& \multicolumn{2}{l}{ value of indicators } & p< \\
\cline { 2 - 4 } & First & Fifth & \\
\hline Summation ability, pulses & & & 0.6 \\
$\quad$ Before exposure & $5.88 \pm 1.68$ & $4.81 \pm 1.14$ & 0.2 \\
After exposure & $10.41 \pm 1.79$ & $6.54 \pm 2.09$ & - \\
p< & 0.1 & 0.5 & 0.3 \\
Muscle tone & & & 0.5 \\
Before exposure & $5.63 \pm 0.2$ & $6.03 \pm 0.17$ & - \\
After exposure & $4.83 \pm 0.22$ & $5.30 \pm 0.27$ & 0.7 \\
p< & 0.01 & 0.01 & 0.9 \\
Static workability, s & & & - \\
Before exposure & $72.60 \pm 18.9$ & $69.10 \pm 25.70$ & 0.1 \\
After exposure & $27.30 \pm 19.40$ & $18.27 \pm 7.70$ & \\
p< & 0.001 & 0.1 & \\
\hline
\end{tabular}

have shown that if a white mouse is held in the vertical position, the hind limbs spread with the weakening of the muscle tone, and the distance between the outer fingers increases. The distance reduces when the muscle tone increases. This integral and very important test, which showed the functional state of the CNS, proved that after the first and fifth exposures of white mice to benzene, the muscle tone increased $(\mathrm{p}<0.01)$. However, we did not find a distinct difference in the muscle tone between the first and fifth exposures $(0.80$ to 0.73 on the average).

The indicators that show the functional state of the CNS include performing static muscular work by the experimental animals.

We found that after the first exposure, a considerable decrease in the static workability was observed in the animals (the time of suspending on the lace decreased from $72.60 \pm 18.9 \mathrm{~s}$ to $27.30 \pm 19.40 \mathrm{~s}, \mathrm{p}<0.001$ ). Table 3 shows a considerable reduction of static workability of animals after the fifth exposure was on the verge of the statistical significance.

If we take into account that the performing of static work is directly related to the muscle tone that is dependent on the cholinergic structures, it may be stated that adaptation to the toxic action has little effect on the parasympathetic nervous system upon excitation of the sympathetic one. This conclusion was confirmed by the method of centrifugation after recovery of the experimental animals from narcosis.

On the day of exposure, after the above studies, the animals were centrifuged at the speed of 600-700 rpm for $20 \mathrm{~s}$, of which $10 \mathrm{~s}$ - with the centrifuge on and $10 \mathrm{~s}$ - with the centrifuge off and decreasing rotation speed. The resulting vestibular irritation results in immobility of animals. After that, the animals make circular movements (vestibular disorders), after which they acquire the ability to move in the rectilinear manner.

Examination of the experimental animals after single and repeated (5 times) inhalation poisoning showed that after the last exposure, the time of rectilinear movement recovery in minutes had decreased on the average by $24.7 \%$, mainly due to shortened duration of "animal hypnosis" (54.9\%) while duration of the vestibular disorders had decreased only by $7.0 \%$. It should be noted that the minimum narcotic concentration of gasoline is $65.7 \%$, and benzene - only $32.9 \%$ from the concentration of acetone, and $50.2 \%$ from the concentration of gasoline. Meanwhile, cortical balance disorders, excitation and inhibition occur earlier under the action of gasoline and especially of benzene. With that, the reaction of females shows a greater excitement than the reaction of males.

\section{DISCUSSION}

The results of acute experiments have shown that one-time action of the substances causes changes in the performance of the CNS. The effect on the nervous system was manifested, first of all, in the narcotic effect characterized by successive phases of excitation and inhibition, which are different for different substances with various time of occurrence and duration (Fig. 1).

The repeated exposure to narcotics is accompanied by the reduced duration of animals staying in the drugged state. For example, in case of 5 times exposure of animals to benzene, this duration is reduced from $34.60 \pm 3.05 \mathrm{~min}$ to $12.27 \pm 3.71 \mathrm{~min}$, which is estimated as the occurrence of animals' adaptation to the action of benzene due to the mobilization of the organism's protective reactions, which is to some extent determined by the CNS state. It should be noted that the studied narcotics' exiting effect on the CNS with subsequent inhibition in case of a single exposure, and the development of animals' adaptation to the repeated exposure to the substances are 


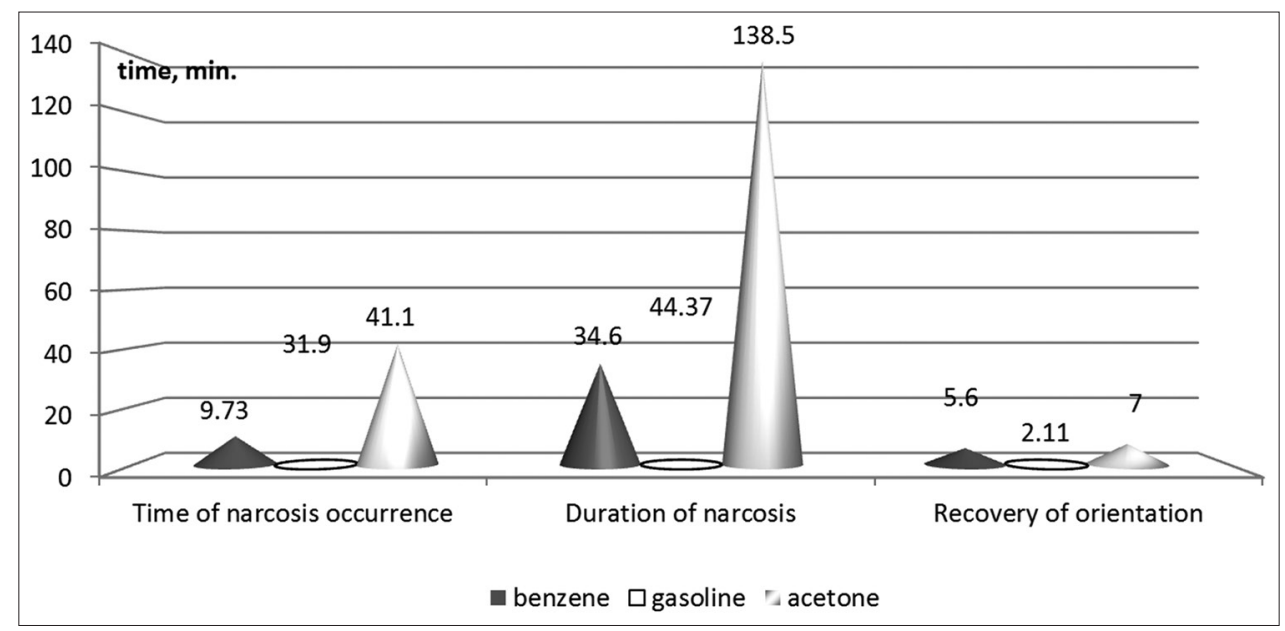

Fig.1: The results of narcotic action of the studied hydrocarbons on rats in case of a single exposure

confirmed by the use of a number of integral tests (CNS's ability to sum the subliminal impulses, the muscle tone, static workability). For example, the reduced number of subliminal pulses from 10.41 to 6.54 , in case of the single and repeated exposure, respectively, the increased muscle tone from 4.83 to 5.30 , as well as the improved static workability of animals in case of the repeated exposure are the evidences of the fact that the occurred adaptation to the repeated action of the substances results in the decreased excitability of the CNS. It is known that an animal staying immobilized is an indicator of the CNS functional state. The restored movement is considered to be a consequence of generalization of the subcortical excitement. It is related to pulses from the muscles due to the abnormal body position. The immobility phase is similar to the state called "animal hypnosis." It should be noted that the vegetative nervous system with participation of hypothalamus is involved in the "animal hypnosis." With that, acetylcholine prolongs, and adrenaline shortens the duration of the animal hypnosis [14]. Pavlov considered the "animal hypnosis" to be a self-protective reflex that occurs in the cerebral cortex, and spreads to the underlying centers. When the functional state of the CNS is restored, the animals acquire the ability to move rectilinearly $[14,15]$. The obtained data are consistent with the scientific ideas about assessing the functional state of the CNS.

\section{CONCLUSION}

Adaptation to the repeated action of the studied substances is a natural protective reaction of the organism to adverse effects. Many studies have shown the possibility of adaptation to industrial poisons, but it does not always occur, repeated exposures sometimes may result in an increased sensitivity of the organism. The conditions that determine the state of the organism are diverse, and therefore, the problem of adaptation gains particular importance in labor health.

\section{CONFLICT OF INTERESTS}

The authors declare that they have no conflict of interest. It has not been published elsewhere. That it has not been simultaneously submitted for publication elsewhere. All authors agree to the submission to the journal.

\section{AUTHORS CONTRIBUTION}

Ragim Almamed Orujov: Concept, Data collection, and analysis, drafting article, writing manuscript. Rana Anver Jafarova: Data collection, editing of the manuscript

\section{REFERENCES}

1. Neghab M, Hosseinzadeh K, Hassanzadeh J. Early liver and kidney dysfunction associated with occupational exposure to sub-threshold limit value levels of benzene, toluene, and xylenes in unleaded petrol. Saf Health Work 2015;6:312-6.

2. Poli D, Andreoli R, Mutti A, et al. Benzene: Environmental Exposure. Reference Module in Earth Systems and Environmental Sciences; 2016.

3. Clark CR, Schreiner CA, Parker CM, Gray T, Hoffman G. Health assessment of gasoline and fuel oxygenate vapors: Subchronic inhalation toxicity. Regul Toxicol Pharmacol Suppl 2014;70:S18-28.

4. Calderón-Garcidueñas L, Kulesza RJ, Doty RL, D’Angiulli A, Torres-Jardón R. Megacities air pollution problems: Mexico city metropolitan area critical issues on the central nervous system pediatric impact. Environ Res 2015;137:157-69.

5. Barton C. Benzene. Reference Module in Biomedical Sciences, from Encyclopedia of Toxicology. 3rd ed.,Vol. 1. San Diego, CA: Academic Press; 2014. p. 415-8.

6. Ratushnyak AA, Andreeva MG, Trushin MV. Influence of the pyrethroid insecticides in ultralow doses on the freshwater invertebrates (Daphnia magna). Fresenius Environ Bull 2005;14:832-4.

7. Nerkar D, Mukherjee A, Mehta BK. Sugatobanerjee metabolic syndrome associated complications. Int J Pharm Pharm Sci 2015;7:22-5.

8. Izmerov NF, Denisov EI, Prokopenko LV, Sivotchalova OV, Stepanian IV, Yu TM. Metodologiyavyyavleniyaiprofilaktikizabolevanij, svyazannyh $\mathrm{s}$ rabotoj [Methods of detecting and preventing occupation-related diseases]. Occup Med Ind Ecol 2010;9:1-7.

9. Ali MU, Liu G, Yousaf B, Abbas Q, Ullah H, Munir MA, et al. Pollution characteristics and human health risks of potentially (eco) toxic elements (PTEs) in road dust from metropolitan area of Hefei, China. Chemosphere 2017;181:111-21.

10. Chen Y, Sun P, Guo X, Gao A. MiR-34a, a promising novel biomarker for benzene toxicity, is involved in cell apoptosis triggered by 1,4-benzoquinone through targeting bcl-2. Environ Pollut 2017;221:256-65.

11. Elfasakhany A. Performance and emissions analysis on using acetonegasoline fuel blends in spark-ignition engine. Eng Sci Technol Int J 2016;19:1224-32.

12. Gajjar RM, Kasting GB. Absorption of ethanol, acetone, benzene and 1,2-dichloroethane through human skin in vitro: A test of diffusion model predictions. Toxicol Appl Pharmacol 2014;281:109-17.

13. Ostrom QT, Bondy ML, Barnholtz-Sloan JS. Reference Module in Biomedical Sciences. Brain and Central Nervous System Tumors: Elsevier; 2015.

14. Devi SA, Bawankar R, Babu S. Current status on biological activities of Acorus calamus-a review. Int J Pharm Pharm Sci 2014;6:66-71.

15. Devi SA, Bawankar R, Babu S. Current status on biological activities of Acorus calamus. Int J Pharm Pharm Sci 2014;6:66-71.

16. Bandyopadhyay D, Ghosh D, Chattopadhyay A, Mitra E. Curry leaves as alternative medicine in heavy metal induced occupational health hazards. Int J Pharm Pharm Sci 2016;8:8-20 